\title{
INNATE IMMUNITY TO MALARIA
}

\section{Mary M. Stevenson ${ }^{*}$ and Eleanor M. Riley}

Malaria is a major cause of disease and death in tropical countries. A safe and effective vaccine is essential to achieve significant and sustained reductions in malaria-related morbidity and mortality. Driven by this need, research on the immunology of malaria has tended to focus on adaptive immunity. The potential for innate immune mechanisms to provide rapid protection against malaria has been largely neglected. On the basis of data from animal models, and clinical and epidemiological studies, this review considers the potential for innate immune mechanisms directed against Plasmodium parasites both to contribute to protection from malaria and to modulate adaptive immune responses.

Malaria, together with HIV and tuberculosis, is one of the main global causes of death from infectious disease, resulting in more than 300 million clinical cases and between one and three million deaths per year. Human malaria is caused by infection with one of four species of the genus Plasmodium (BOX 1) - a protozoan parasite transmitted by the bite of an infected female Anopheles mosquito (FIG. 1). Immunity to malaria is complex, and is essentially both species and stage specific. The generation and maintenance of clinically protective immune responses requires repeated infections over the lifetime of the individual. The main features of the acquired immune response against the various stages of the malaria parasite are shown in BOX 2 (REFS 1-4). Unless restrained by immune mechanisms or by anti-malarial drugs, blood parasitaemia increases exponentially to the point at which almost all of the available erythrocytes are infected and death is inevitable. Innate or adaptive immune effector mechanisms can limit the peak of parasitaemia, prevent severe pathology and reduce the load of circulating infected cells. However, they typically fail to eliminate the infection completely, leading to persistent low-grade parasitaemia, which might frequently fall below the limit of detection by microscopy, but which might persist for many months or years ${ }^{5}$. The rupture of erythrocytic schizonts is typically accompanied by bouts of fever, nausea, headaches and other symptoms of a systemic pro-inflammatory cytokine response, much of which is now believed to derive from cells of the innate immune system ${ }^{6}$.
Plasmodium malariae and Plasmodium ovale are relatively infrequent causes of morbidity, whereas Plasmodium vivax is a common cause of severe, acute febrile illness, especially in Asia and South America, but is rarely fatal. The vast majority of severe malaria cases and deaths are caused by Plasmodium falciparum, which is endemic in most of sub-Saharan Africa and in many other regions of the tropical world. Severe pathology, typically anaemia, metabolic acidosis and/or cerebral malaria, results from the destruction of erythrocytes and bone-marrow suppression accompanied by hypoxia, hypoglycaemia and lactic acidosis, resulting from the increased metabolic demands of the parasite, and impaired circulation owing to peripheral hypotension and adherence of infected erythrocytes to the vascular endothelium. Inflammatory mediators have been repeatedly implicated in the severity of the disease ${ }^{7,8}$, giving rise to the widely held belief that severe malaria is, at least in part, an immune-mediated disease.

Various combinations of rodent Plasmodium species and inbred mouse strains have been used to mimic human malaria infections (BOX 1). However, no single rodent model replicates all of the features of human malaria in terms of either pathology or immune responses $^{8,9}$. For example, cerebral malaria shares many features in humans and mice, although there is controversy concerning the permeability of the blood-brain barrier in adult patients versus mice ${ }^{8}$. However, infections of laboratory mice with Plasmodium chabaudi, Plasmodium berghei, Plasmodium yoelii and Plasmodium 


\section{Box 1 | Plasmodium parasites that cause malaria}

\section{In humans}

- Plasmodium falciparum: causes the most severe form of malaria and can be fatal. Can cause chronic infections (up to 2-3 years), but does not form hypnozoites (dormant stages that persist in hepatocytes) and does not relapse.

- Plasmodium vivax: a major cause of clinical malaria, but is rarely fatal. Distribution is restricted by the absence of Duffy antigen (which determines entry into red blood cells) in African populations. This parasite forms hypnozoites and might relapse many years after apparent cure.

- Plasmodium malariae: infrequent cause of clinical malaria, especially in Africa. Untreated infections can persist as low-grade parasitaemia for several decades.

- Plasmodium ovale: infrequent cause of mild-moderate clinical malaria, but might be found in mixed infections with other species. Forms hypnozoites and might relapse.

In mice

- Plasmodium chabaudi (P. chabaudi chabaudi AS and P. chabaudi adami): used to study immune mechanisms and immunoregulation by cytokines, to identify susceptibility loci and to study the immune basis of pathology. P. chabaudi chabaudi AS causes non-lethal infection in resistant mouse strains and lethal infection in susceptible mouse strains. P. chabaudi adami causes a mild, non-lethal infection.

- Plasmodium berghei (P. berghei ANKA and P. berghei K173): widely used to study pathogenesis. $P$. berghei ANKA serves as a model of experimental cerebral malaria (ECM); there is genetic variation in the development of ECM between inbred mouse strains, which correlates with the production of pro-inflammatory cytokines.

- Plasmodium yoelii (P. yoelii 17XL, P. yoelii 17XNL and P. yoelii YM): used to study immune mechanisms and pathogenesis, including ECM, as recombinant merozoite surface protein 1 (MSP1) is available. P. yoelii $17 \mathrm{XL}$ is widely used to identify vaccine-induced immune responses.

- Plasmodium vinckei: P. vinckei vinckei, which causes a lethal infection, is used to study pathogenesis and for chemotherapy studies; $P$. vinckei petteri, which causes a non-lethal infection, is used to study immune mechanisms.

\section{$\gamma \delta \mathrm{T}$ CELLS}

Although $\gamma \delta$ T-cell receptors are potentially diverse, circulating $\gamma \delta$ T cells express a restricted set of these receptors and seem to recognize a relatively restricted set of ligands; this might reflect postnatal expansion of a small number of $\gamma \delta$ T-cell clones by a few potent antigens, such as those expressed by mycobacteria or other widely distributed bacteria.

\section{SEVERE COMBINED}

IMMUNODEFICIENT (SCID) MICE Mice with this defect in their immune system do not have $\mathrm{B}$ or $\mathrm{T}$ cells and can, therefore, not mount adaptive immune responses.

NUDE MICE

A mutation in mice that causes both hairlessness and defective formation of the thymus, which results in a lack of mature $T$ cells. vinckei have been useful in the investigation of immune mechanisms and pathogenesis, for the identification of genes that regulate susceptibility to malaria, and for vaccine development and chemotherapy studies ${ }^{9-12}$. Genetically controlled variation in susceptibility is evident among inbred mouse strains to several of the rodent Plasmodium species ${ }^{10}$.

Similarly, there are important differences between human and mouse immune systems, including differences in natural killer (NK) cells and dendritic cells (DCs), which are important components of the innate immune response. For NK cells, the differences between humans and mice include divergent evolution of the main classes of polymorphic receptors for MHC and MHC-like molecules (expansion of the Ly49 gene family in mice and the killer cell immunoglobulin-like receptor (KIR) gene family in humans) and variation in the extent to which cells can be activated by cytokines in the absence of other signals ${ }^{13,14}$. Differences between humans and mice in the maturation pathways of DCs, the phenotypes of these cells in the two species and their cytokine production $^{15}$ might account for the discrepancies observed in the interaction of Plasmodium parasites with DCs (discussed later).

\section{What controls parasitaemia?}

A prominent feature of rodent malaria infections, whatever the host-parasite combination, is that survival is linked to the ability to control the replication of bloodstage parasites within the first 7 to 14 days after infection. The mouse model in which the immune response to blood-stage parasites has been most extensively dissected is $P$. chabaudi chabaudi AS infection of C57BL/6 mice (FIG. 2). During infection with $P$. chabaudi chabaudi AS, it is clear that control of the acute phase or the first wave of parasitaemia (primary peak parasitaemia) occurs before the production of marked levels of specific IgG antibodies (FIG. 2a). Both CD4 ${ }^{+} \mathrm{T}$ helper $1\left(\mathrm{~T}_{\mathrm{H}} 1\right)$ cells and interferon- $\gamma($ IFN- $\gamma)$ are absolutely required to control the level of peak parasitaemia ${ }^{1,16-19}$ (FIGS 2b, 2c). The proinflammatory cytokine interleukin-12 (IL-12) is also required ${ }^{16,17} \cdot \gamma \delta$ T-CELL populations are expanded during malaria infection in mice and, although not essential for resolution of infection, in their absence, parasitaemia is prolonged and elimination of parasites is delayed for a few days ${ }^{9}$ (FIG. 2d). CD4 ${ }^{+} \mathrm{T}$ cells and antibody are required to reduce parasitaemia and mediate clearance of the parasites during the chronic phase ${ }^{1}$. Although initial studies indicated that control of parasitaemia after the peak is dependent on $\mathrm{CD}^{+} \mathrm{T}_{\mathrm{H}} 2$ cells ${ }^{1}$, recent studies show that a $\mathrm{T}_{\mathrm{H}} 1$-cell response is required not only during acute infection to promote a cell-mediated immune response, but also during the chronic stage of infection to promote antibody responses ${ }^{16}$.

Acute infections with P. chabaudi chabaudi AS, as well as $P$. chabaudi adami, are controlled in the absence of $\mathrm{B}$ cells, implicating antibody-independent mechanisms in the control of peak parasitaemia ${ }^{1}$ (FIG. 2e). However, in the absence of B cells, $P$. chabaudi chabaudi AS parasitaemia is reduced to low levels but not completely eliminated, stressing the need for both antibody-independent and antibody-dependent mechanisms for complete clearance of blood-stage malaria parasites. Furthermore, both SEVERE COMBINED IMMUNODEFICIENT (SCID) MICE and NUDE MICE exhibit ascending and peak parasitaemia levels that are similar to intact mice after infection with $P$. chabaudi chabaudi $\mathrm{AS}^{20}$ or with non-lethal P. yoelii ${ }^{21}$, but the ability of these mice to control parasitaemia is transient in the absence of both T and B cells, and high mortality occurs later in infection.

Taken together, evidence from the P. chabaudi chabaudi AS model of blood-stage malaria highlights the importance of adaptive, $\mathrm{CD} 4^{+} \mathrm{T}$-cell-dependent mechanisms for the control of blood-stage malaria. Accumulating evidence, however, also indicates a crucial role for innate immune responses in protective immunity to malaria. For example, in the absence of NK cells, peak parasitaemia is higher during acute infection with P. chabaudi chabaudi AS and there is marked recurring parasitaemia during the chronic phase $^{22}$ (FIG. 2f). It has been observed that early production of IFN- $\gamma$ by NK cells is associated with spontaneously resolving infection in mice infected with various Plasmodium species, whereas lethal infection occurs in the absence of early IFN- $\gamma$ production by NK cells and possibly $\gamma \delta \mathrm{T}$ cells ${ }^{22,23}$. 


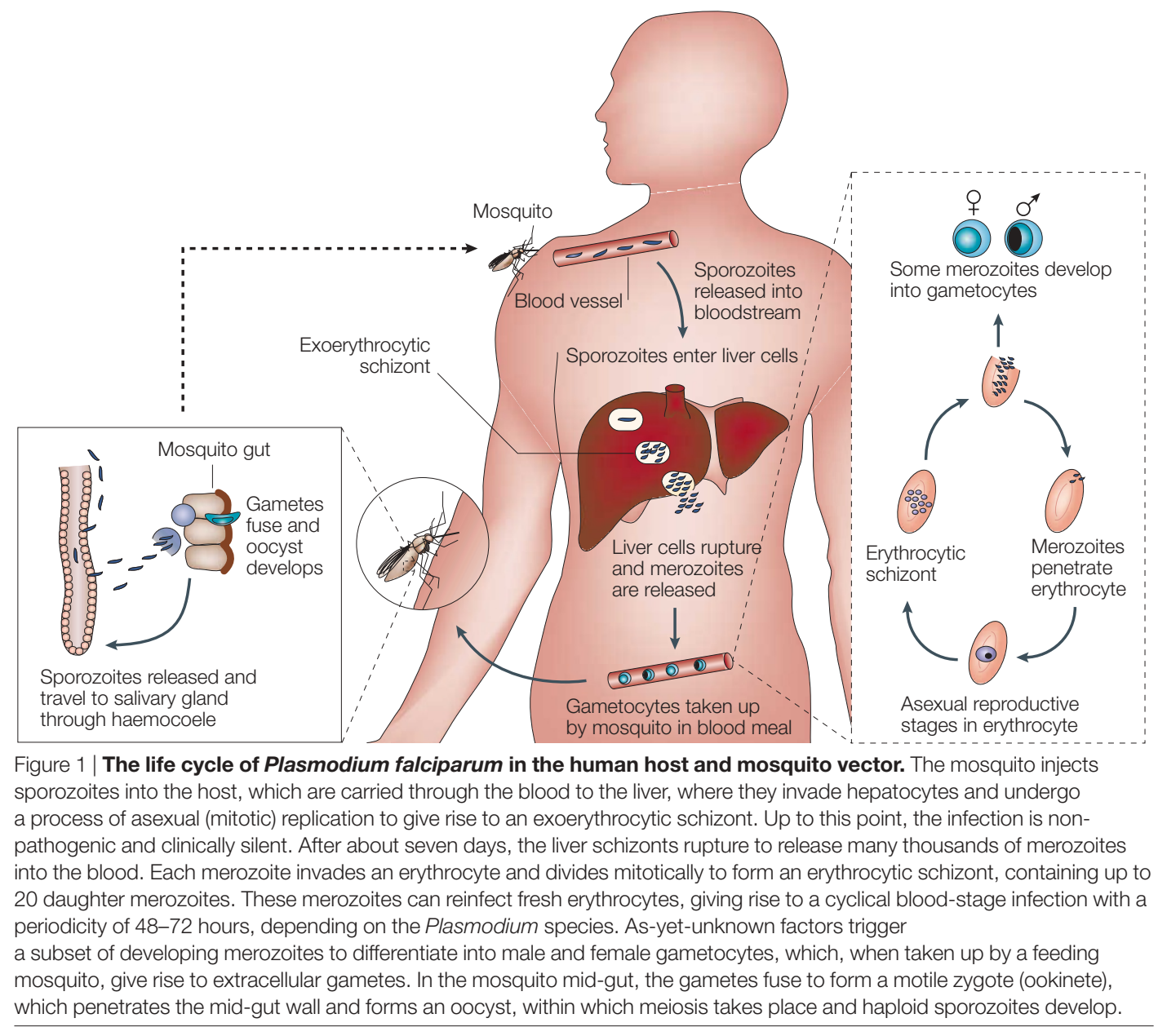

Clinical studies support the observations made in infected mice and indicate that innate responses contribute to the control of primary malaria infection in humans. Before the introduction of antibiotics, malaria therapy was used to induce high fevers as a treatment for neurosyphilis; recent re-analysis of the clinical records of repeated infections in these non-immune patients has revealed that the density of parasitaemia at which parasite growth is controlled (that is, the peak

\section{Box 2 | Presumed mechanisms of adaptive immunity to malaria}

- Antibodies block invasion of sporozoites into liver cells

- Interferon- $\gamma\left(\right.$ IFN- $\gamma$ ) and $\mathrm{CD}^{+} \mathrm{T}$ cells inhibit parasite development in hepatocytes

- Antibodies block invasion of merozoites into erythrocytes

- Antibodies prevent sequestration of infected erythrocytes by preventing binding to adhesion molecules on the vascular endothelium

- IFN- $\gamma$ and $\mathrm{CD}^{+}{ }^{+} \mathrm{T}$ cells activate macrophages to phagocytose intra-erythrocytic parasites and free merozoites

- Antibodies neutralize parasite glycosylphosphatidylinositol and inhibit induction of the inflammatory cytokine cascade

- Antibodies mediate complement-dependent lysis of extracellular gametes, and prevent fertilization of gametes and the development of zygotes

For a detailed discussion of these mechanisms, please see REFS 1-4. parasitaemia) is highly predictable in an individual, and is independent of the strain or species of the infection. The authors concluded that the data were best explained by induction of innate immune mechanisms ${ }^{24}$. Although a range of genetic factors might explain the variation between individuals in their peak parasite density, one explanation, suggested by the authors, is that humans might vary in their ability to make a rapid innate immune response ${ }^{25-41}$ (TABLE 1).

A recent study of experimental $P$. falciparum infections in malaria-naive individuals has shown a coordinated increase in the levels of pro-inflammatory cytokines, including IFN- $\gamma$, IL-12p40 and IL-8, in the serum at the time of parasite emergence from the liver and the first appearance of parasitized erythrocytes ${ }^{42}$. This provides in vivo corroboration of in vitro studies in which parasitized erythrocytes have been shown to induce tumour-necrosis factor (TNF), IL-12 and IFN- $\gamma$ production by peripheral-blood mononuclear cells (PBMCs) of naive donors within 10 hours ${ }^{43}$. More recently, observations in populations exposed to repeated malaria infections ${ }^{44}$ have provided empirical support for the hypothesis, generated from mathematical model ${ }^{45}$, that innate immune mechanisms are triggered when parasite density crosses a predefined threshold. This leads to oscillation of blood parasite densities between 
CYTOPHILIC ANTIBODY Opsonizing antibody subclasses in mice (IgG2a and IgG2b) and in humans (IgG1 and IgG3), which mediate phagocytosis by macrophages. a lower level (at which immune effector responses are not induced) and a higher level (at which innate effector mechanisms are triggered and partial clearance of infected cells ensues). Innate immune mechanisms therefore function to limit the maximum parasite density, but gradually acquired adaptive mechanisms are required for complete parasite elimination. Importantly, these density-dependent mechanisms seem to limit the growth of all blood-stage parasites, irrespective of species or strain, indicating that innate immunity is triggered by molecules that are conserved between different species and strains of Plasmodium, and might explain the frequently observed lack of mixed species infections in populations in which many Plasmodium species are circulating at high frequency ${ }^{46,47}$.

So, the kinetics of malaria infections in both mice and humans indicate that innate responses are essential to limit the initial phase of parasite replication, controlling the first wave of parasitaemia and allowing the host time to develop specific adaptive responses that will enable the infection to be cleared. By ameliorating the early phase of infection, innate immunity essentially reduces the virulence of the infection (reducing the likelihood of early host death) and so increases the chances that the parasite will be transmitted
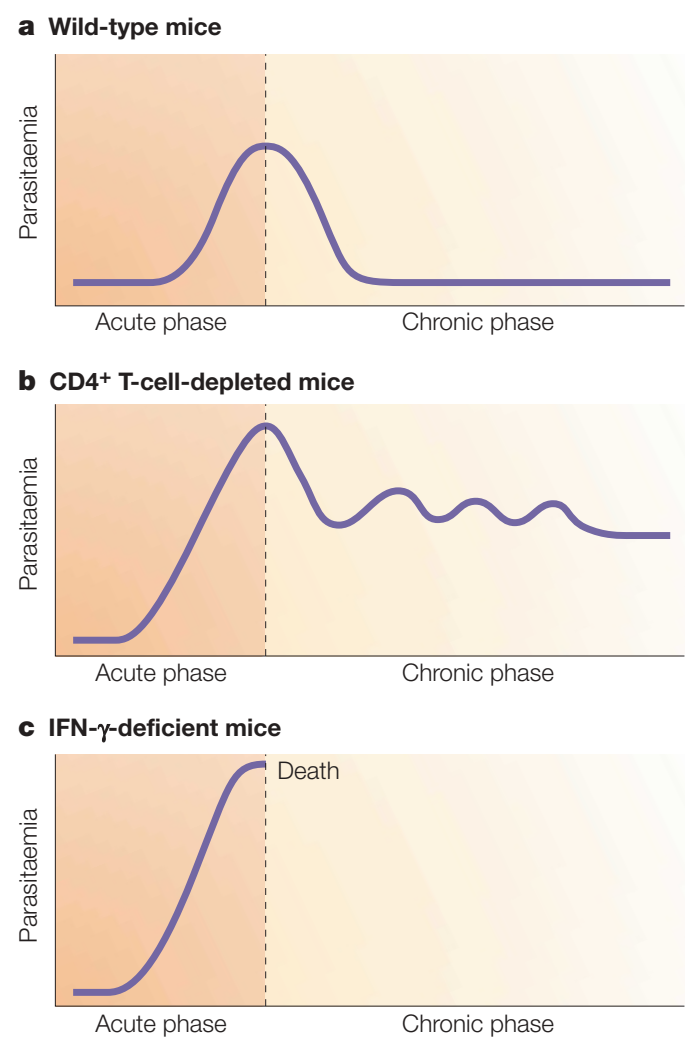

to the next host. From an evolutionary perspective, therefore, it would seem advantageous to the host to make an innate response and advantageous to the parasite to induce it, although it could be argued that in areas of intense malaria transmission (where concurrent infection by more than one parasite genotype, or strain, is common), competition between parasite strains might select for resistance to innate immune effector mechanisms ${ }^{48}$.

\section{Innate immunity to malaria}

Unlike other infections with intracellular pathogens, including viruses, bacteria and some protozoan parasites, in which the role of the innate immune response has been well investigated during the past few years ${ }^{4-52}$, relatively few studies have addressed the role of innate immunity to malaria in either mouse models or humans. A key question that needs to be resolved is the identity of the antigen-presenting cells (APCs) that activate $\mathrm{T}$ cells, particularly the $\mathrm{CD} 4^{+} \mathrm{T}_{\mathrm{H}} 1$ cells that produce IFN- $\gamma$ and mediate class switching to the protective CүтOPHILIC ANTiBODy subclasses IgG2a and IgG2b (in mice) or IgG1 and IgG3 (in humans) during acute infection ${ }^{1,16}$. Bone-marrow-derived DCs, macrophages and B cells isolated from immune mice have all been shown to have
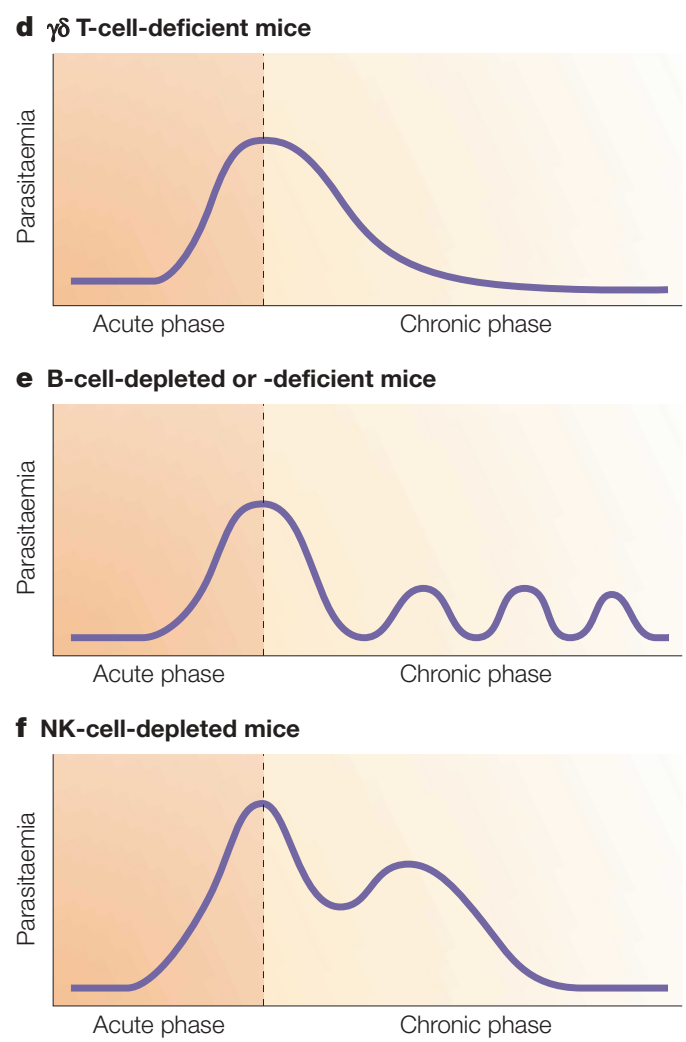

Figure 2 | Representative course of infection with Plasmodium chabaudi chabaudi AS. Shown for wild-type mice (a), CD4+ T-cell-depleted mice (b), interferon- $\gamma($ IFN- $\gamma$ )-deficient mice (c), $\gamma \delta$ T-cell-deficient mice (d), B-cell-depleted or B-cell-deficient mice (e) and natural killer (NK)-cell-depleted mice (f). Note that infection consists of an acute phase and a chronic phase. In intact wild-type mice, the first wave of parasitaemia (peak parasitaemia) is controlled during the acute phase by a CD4+ Thelper $1\left(T_{H} 1\right)-$, IFN- $\gamma^{-}$ dependent mechanism that is antibody independent. The parasite is eliminated during the chronic phase by a mechanism that requires both $\mathrm{CD} 4{ }^{+} \mathrm{T}$ cells and malaria-specific antibody. Depletion or deficiency of CD4+ $T$ cells or NK cells alters the course of infection during both the acute and chronic phases, whereas depletion or deficiency of B cells alters the course of infection during the chronic phase only. $\gamma \delta$ T cells are not essential for resolution of infection. Based on data from REFS 1,9,16-19. 
UNMETHYLATED CPG MOTIFS Sequences in bacterial DNA recognized by the mammalian immune system, which consist of unmethylated $\mathrm{CPG}$ dinucleotides in certain base contexts. the capacity to present malaria antigens to $\mathrm{T}$ cells ${ }^{53}$. During infection with $P$. yoelii, there is upregulation of expression of MHC class II molecules and CD80 and continued expression of CD86 by splenic DCs, macrophages and $\mathrm{B}$ cells ${ }^{54}$. These cell populations can process and present antigen and support IFN- $\gamma$, but not IL-2, production by T cells ${ }^{54}$. Inhibition of IL-2 production by APCs might be a possible explanation for the long-standing observation of suboptimal responses to unrelated antigens during acute malaria ${ }^{55,56}$.

Macrophages. In addition to the function of macrophages as APCs in malaria, studies in humans and mice indicate an important role for mononuclear phagocytes in innate immunity to malaria due to their ability to phagocytose infected erythrocytes in the absence of cytophilic or opsonizing malaria-specific antibody ${ }^{57}$. Recent studies by Kain and colleagues ${ }^{57}$ indicated a role for scavenger receptors, including the class $\mathrm{B}$ receptor $\mathrm{CD} 36$, in opsonin-independent phagocytosis of $P$. falciparum-infected erythrocytes by monocytes from non-immune individuals. This interaction probably involves binding of CD36 to the P. falciparum-encoded erythrocyte membrane protein 1 (PfEMP1) on infected cells and does not contribute to pro-inflammatory cytokine production by monocytes/macrophages. Adherence of infected erythrocytes to CD36 might modulate the adaptive immune response, as well as influence the severity of infection. However, macrophages might be more important during adaptive immunity as effector cells that can mediate antibody-dependent cellular inhibition or the production of anti-parasite molecules, such as nitric oxide, after their activation by $\mathrm{CD} 4^{+}$T-cell-derived IFN- $\gamma^{1-3}$.
Dendritic cells. DCs are APCs that have a central role in both innate and adaptive immune responses, especially in response to microbial infections, because of their unique ability to sample sites of pathogen entry, respond to microbial signals, uptake and process antigens, and activate both naive and memory $\mathrm{T}$ cell ${ }^{58,59}$. Although the malarial ligands that induce innate responses, and their respective receptors, are only just beginning to be characterized $^{57,60-72}$ (TABLE 2), activation of DCs and possibly macrophages might be one of the earliest events in the innate response to malaria. Toll-like receptors (TLRs), which comprise a family of at least ten members, are a major class of pattern-recognition receptors (PRRs) that are essential for recognition of a range of microbial products derived from bacteria, fungi and protozoan parasites ${ }^{73}$. TLRs, as well as other PRRs, have a role in activating innate immunity and modulating adaptive immune responses to microbial pathogens, including intracellular protozoan parasites ${ }^{74}$. Their role in immunity to malaria has not been firmly established, although this area is under investigation in several laboratories. A study by Adachi et al..$^{65}$ showed that blood-stage infection with $P$. berghei in mice induces liver injury by a TLR-myeloid differentiation factor 88 (Myd88)-dependent signalling pathway that requires IL-12. The TLR involved was not identified, although mice deficient for Tlr2, Tlr4 or Tlr6 all displayed liver injury and IL-12 levels that were similar to wild-type mice. This indicates ligation of other TLRs and/or simultaneous ligation of many TLRs by components of malaria parasites. The potential for TLR-mediated signals to contribute to anti-parasite mechanisms has been shown in studies in which injection of UNMETHYLATED CPG MOTIFs conferred resistance to sporozoite-induced

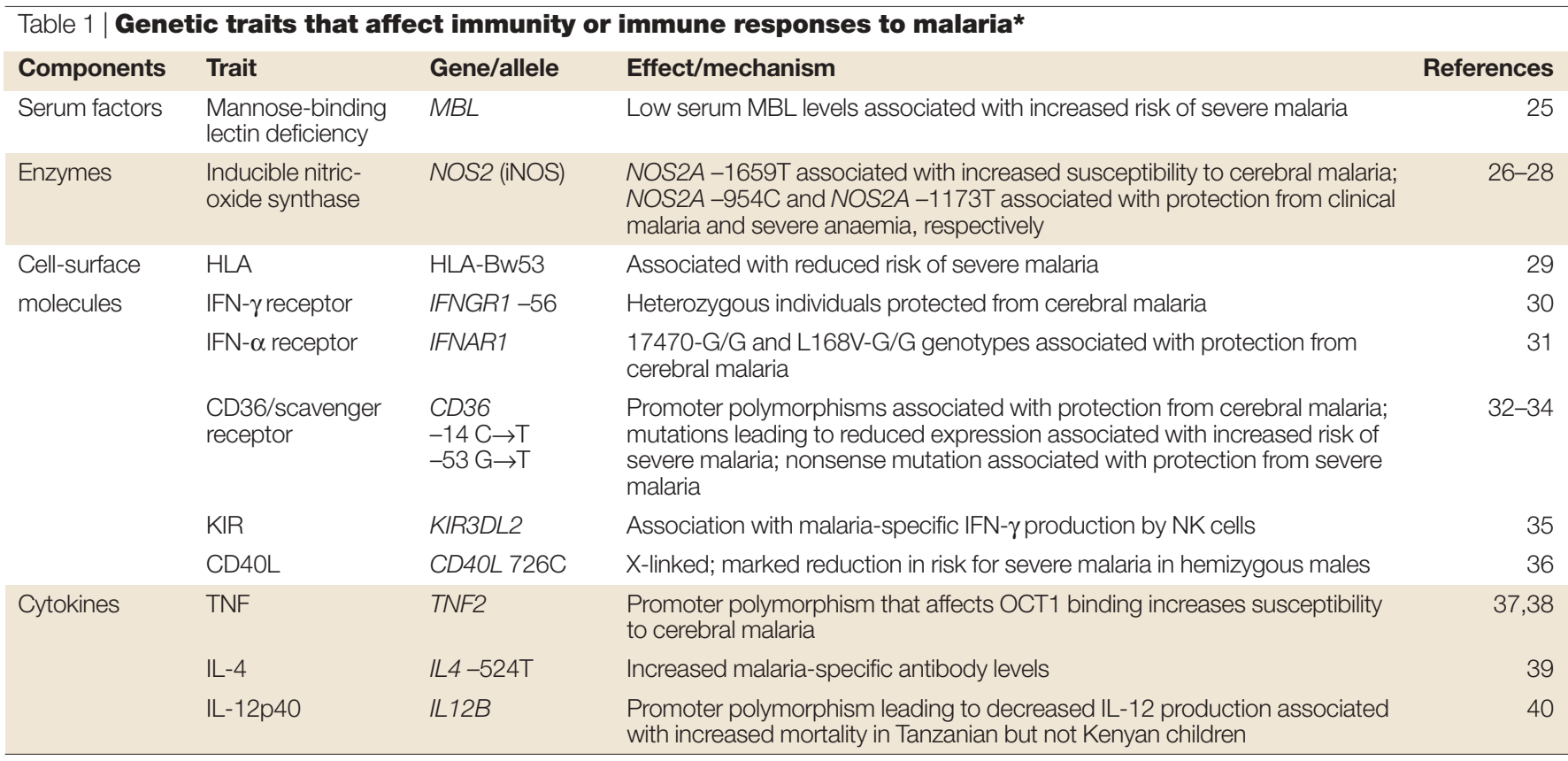

*Data apply to infection with Plasmodium falciparum. For a more complete review of the genetics of susceptibility to malaria see REF. 41 . See Online links box for a web site featuring a regularly updated list of genetic determinants of susceptibility to malaria. CD4OL, CD40 ligand; IFN, interferon; IL, interleukin; KIR, killer cell immunoglobulin-like receptor; MBL, mannose-binding lectin; NK, natural killer; TNF, tumour-necrosis factor. 


\begin{tabular}{|c|c|c|c|c|}
\hline Cell & Host receptor & Parasite ligand & Evidence & References \\
\hline Dendritic cell & CD36 & $\begin{array}{l}\text { PfEMP1? } \\
\text { Phosphatidylserine? }\end{array}$ & $\begin{array}{l}\text { P. falciparum-infected erythrocytes bind to DCs through CD36 and modulate } \\
\text { their function. CD36 mediates non-opsonic phagocytosis of infected erythrocytes }\end{array}$ & $57,60-62$ \\
\hline$\gamma \delta$ T cell & $\gamma \delta$-TCR & $\begin{array}{l}\text { Monophosphate and } \\
\text { diphosphate esters; } \\
\text { MALag1 and MALag2 }\end{array}$ & $\begin{array}{l}\text { Proliferation and cytotoxicity of human } \mathrm{V} \gamma \mathrm{g} / \mathrm{N} \alpha 2 \mathrm{~T} \text {-cell clones. Upregulation } \\
\text { of CD69 expression and IFN- } \gamma \text { production is induced by purified P. falciparum } \\
\text { schizont lysate }\end{array}$ & 66,67 \\
\hline NK cell & Unknown & Unknown & $\begin{array}{l}\text { Direct contact between NK cell and infected erythrocyte is required for full } \\
\text { NK-cell activation } \\
\text { NK cells are cytotoxic for infected erythrocytes }\end{array}$ & $\begin{array}{l}35 \\
68\end{array}$ \\
\hline NKT cell & V $\alpha 14 N \beta 8$ TCR & GPI & $\begin{array}{l}\mathrm{NK} 1.1^{+}, \mathrm{CD} 1 \mathrm{~d} \text {-restricted T cells proliferate and produce IL-4 in response } \\
\text { to purified GPI }\end{array}$ & 69 \\
\hline \multirow[t]{2}{*}{$\begin{array}{l}\text { Soluble } \\
\text { factors }\end{array}$} & $\mathrm{MBL}$ & Surface sugars & $\begin{array}{l}\text { Reduced levels of serum MBL are associated with increased risk of severe } \\
P \text {. falciparum malaria } \\
\text { MBL-A deficiency does not affect hepatic invasion by } P \text {. yoelii sporozoites } \\
\text { MBL binds glycoproteins on infected erythrocytes, but does not affect parasite } \\
\text { growth }\end{array}$ & $\begin{array}{l}25 \\
70 \\
71\end{array}$ \\
\hline & N.D. & $\begin{array}{l}\text { PxSR (scavenger } \\
\text { receptor homologue) }\end{array}$ & $\begin{array}{l}\text { PxSR might prevent activation of innate mechanisms in mosquitoes } \\
\text { by competition with mosquito scavenger receptors }\end{array}$ & 72 \\
\hline
\end{tabular}

DC, dendritic cell; GPI, glycosylphosphatidylinositol; IFN- $\gamma$, interferon- $\gamma$; IL, interleukin; MBL, mannose-binding lectin; Myd88, myeloid differentiation factor 88; N.D., not determined; NK, natural killer; P. berghei, Plasmodium berghei; P. falciparum, Plasmodium falciparum; P. yoelii, Plasmodium yoelii; PfEMP1, P. falciparum-encoded erythrocyte membrane protein 1; TCR, T-cell receptor; TLR, Toll-like receptor; TNF, tumour-necrosis factor.

MIXED LYMPHOCYTE REACTION (MLR). When peripheral-blood mononuclear cells or splenocytes from MHC-disparate donors are mixed together in the same culture, Thelper cells from each donor recognize allogeneic $\mathrm{MHC}$ molecules on antigen-presenting cells from the other donor, and the $T$ helper cells are induced to proliferate and release cytokines. infections in mice ${ }^{75}$. Stimulation through TLR-mediated signals might also be useful to enhance vaccine-induced immunity, as shown by recent studies using unmethylated CpG motifs as adjuvant for immunization against blood-stage malaria infection in the P. chabaudi chabaudi $\mathrm{AS}^{76}$ and P. yoelii ${ }^{77}$ models.

Evidence that malaria parasites interact with DCs to promote inflammatory responses is limited and controversial. Some studies indicate that Plasmodium parasites inhibit normal DC maturation. In vitro studies carried out by Urban and colleagues ${ }^{61}$ revealed that $P$. falciparum-infected erythrocytes bind to CD36 on the surface of human peripheral-blood-derived DCs and inhibit normal lipopolysaccharide (LPS)-induced upregulation of expression of MHC class II molecules, intercellular adhesion molecule 1 (ICAM1), CD40, CD80, CD83 and CD86. P. falciparum-exposed DCs were found to secrete IL-10 rather than IL-12, and their ability to activate $\mathrm{T}$ cells in an allogeneic MIXED LYMPHOCYTE REACTION or to activate memory CD $4^{+}$ $\mathrm{T}$ cells was markedly reduced. Results of in vitro as well as in vivo studies of infections with $P$. yoelii in mice are consistent with these findings ${ }^{78}$. Conversely, studies in the P. yoelii ${ }^{79}$ and $P$. chabaudi chabaudi AS models ${ }^{80}$ (R. Ing, Z. Su and M.M.S., unpublished observations) show that DC maturation and activation are not perturbed by in vitro or in vivo exposure to blood-stage parasites. Recently, we have observed that $P$. falciparum-infected erythrocytes induce IL-12 production by peripheral-blood adherent cells of naive donors within 18 hours (M. Walther, M. Nassar and E.M.R., unpublished observations). Furthermore, purified haemozoin — the insoluble residue of haemoglobin that accumulates in phagocytes - from P. falciparum induces DC maturation, as evidenced by the upregulation of expression of co-stimulatory molecules and marked increases in IL-12 production $^{81}$; haemozoin did not alter LPS-induced IL-12 production. Moreover, administration of haemozoin to $\mathrm{BALB} / \mathrm{c}$ mice together with a DNA vaccine encoding Pfs 25 - a sexual stage antigen - markedly increased the ratio of cytophilic IgG2a to non-cytophilic IgG1 antibodies compared with the group that received the DNA vaccine alone; haemozoin potentiated vaccine efficiency through the promotion of $\mathrm{T}_{\mathrm{H}} 1$-cell responses ${ }^{81}$.

So, DC activation by malaria parasites seems to be normal in some in vitro and in vivo systems, but is abnormal in other experimental systems. One potential explanation is that an initial, but transient, period of conventional APC/DC activation might be followed by a refractory period during which pro-inflammatory signals are absent or actively downregulated to prevent pathology. The in vivo relevance of possible downregulation of DC maturation by Plasmodium during malaria infection is not yet clear; as, despite reports of possible functional impairment of DCs in malaria-infected children ${ }^{82}$, marked pro-inflammatory cytokine responses are generated during malaria infections. Plasma levels of DC- and macrophage-derived cytokines are upregulated within hours of the emergence of parasitized erythrocytes in the circulation of humans ${ }^{42}$ and mice $^{17}$, and are required for protection ${ }^{17,83}$. In humans, low levels of plasma IL-12 (REFS 84-86) and IL-18 (REF. 87) are associated with severe malarial pathology and, in prospective epidemiological studies, IL-12 production is inversely associated with risk of infection and positively associated with haemoglobin concentration (indicative of protection from malarial anaemia), and IFN- $\gamma$ and TNF production ${ }^{88}$. Further studies both in vitro and in vivo are required to resolve the conflicting data on the induction and modulation of APC function by malaria. 
NKT CELLS

A heterogeneous population of lymphocytes with phenotypic and functional characteristics of both classical T cells and natural killer (NK) cells. Classical mouse NKT cells express the NK1.1 cell-surface marker, are T-cell receptor (TCR) V $\alpha 14^{+}$, recognize lipidcontaining antigen in the context of the non-classical MHC class I molecule CD1d and are selectively activated by the synthetic ligand $\alpha$-galactosylceramide. Various unconventional $\mathrm{T}$ cells have also now been described that express a diverse array of TCRs and are not CDId restricted.
NKT cells. The potential for NKT CELLS to contribute to anti-malarial immunity, particularly against developing pre-erythrocytic parasites in hepatocytes, has been shown by Tsuji and colleagues ${ }^{89}$, who report that $\alpha$-galactosylceramide ( $\alpha$-GalCer), when administered to mice infected with sporozoites of $P$. yoelii and $P$. berghei, inhibits the development of intrahepatocytic parasites and prevents the onset of blood-stage infection. The demonstration that $\alpha$-GalCer also enhances vaccine-induced immunity to pre-erythrocytic parasites ${ }^{89}$ is a good example of the cross-talk between the innate and adaptive immune systems. However, the question of whether NKT cells are an essential component of immunity to liver-stage parasites is not resolved. Infection of mice with $P$. yoelii sporozoites has been reported to lead to an increase in the number of activated CD $4^{-} \mathrm{CD} 8^{-} \mathrm{NK} 1.1^{+} \alpha \beta$-T-cell receptor $(\alpha \beta-\mathrm{TCR})^{+}$cells in the liver, and these cells inhibited parasite growth in in vitro hepatocyte cultures in an IFN- $\gamma$-dependent manner ${ }^{89}$. Similarly, NK1.1 $1^{+} \alpha \beta-\mathrm{TCR}^{+}$cells in the livers of athymic (nude) mice are required for partial protection against low-dose infection with $P$. yoelii-infected erythrocytes, and NK1.1 ${ }^{+} \alpha \beta-\mathrm{TCR}^{+}$cells from the livers of these mice that had recovered from a $P$. yoelii infection were able to passively transfer resistance to naive mice $^{89}$. It has been reported that IgG antibody responses to glycosylphosphatidylinositol (GPI)-anchored protein antigens of pre-erythrocytic parasites (for example, the circumsporozoite protein) are regulated through CD1drestricted recognition of GPI by CD $4^{+} \mathrm{NK} 1.1^{+}$cells $^{69}$. More recently, Schofield and colleagues ${ }^{90}$ have reported that CD1d-restricted NKT cells from mice of different genetic backgrounds influence the polarization of $\mathrm{T}_{\mathrm{H}} 1$ versus $\mathrm{T}_{\mathrm{H}} 2$-cell responses, cytokine production and pathogenesis in P. berghei ANKA infections, and suggested that the function of mouse NKT cells is influenced by genes in the NK complex ${ }^{90}$. Then again, CD1d-deficient mice show no apparent defects in their immune response to $P$. berghei sporozoites, including apparently normal circumsporozoite-protein-specific antibody responses, indicating that CD1d-restricted NKT cells are not essential for resistance to liver-stage infection ${ }^{89}$. Furthermore, studies with another intracellular protozoan parasite (Trypanosoma cruzi) indicate that although protozoan-derived GPI-anchored moieties are natural ligands of CD1d, they fail to activate NKT cells directly ${ }^{91}$, and indicate that induction of IL-12 production by APCs through GPI binding to TLRs ${ }^{74}$ might be required for NKT-cell activation. Studies of the role of NKT cells in immunity to malaria in humans have not been reported.

$\gamma \delta T$ cells. Similar to NKT cells, $\gamma \delta$ T cells seem to bridge innate and adaptive immune responses. Polyclonal expansion of the $\gamma \delta$ T-cell subset has been reported in acute infection with $P$. falciparum ${ }^{92,93}$ and $P$. vivax, including primary infections ${ }^{92}$. Although the clinical relevance of $\gamma \delta$ T-cell activation has not been properly evaluated, $P$. falciparum-activated $\gamma \delta$ T cells produce large amounts of IFN- $\gamma^{93,94}$ and have been reported to have anti-parasite functions ${ }^{95}$. The malarial ligands for human $\gamma \delta \mathrm{T}$ cells have been identified as soluble, schizont-associated phosphorylated non-peptide antigens ${ }^{66,67}$, similar to those described from mycobacteria $^{96,97}$. In addition to activation through the TCR, malaria-responsive $\gamma \delta$ T cells require exogenous cytokines that signal through common- $\gamma$-chain-containing receptors $^{98,99}$, indicating that $\gamma \delta \mathrm{T}$-cell responses might be secondary to activation of other cell types, including monocytes ${ }^{67}$, T cells ${ }^{98,100}$ and NK cells (see later), and possibly explaining why $\gamma \delta$ T cells respond preferentially to live parasites ${ }^{99}$.

In mice, $\mathrm{CD}^{+} \mathrm{T}$-cell-dependent expansion of splenic $\gamma \delta \mathrm{T}$-cell populations has been found during acute blood-stage infection with $P$. chabaudi adami and $P$. chabaudi chabaudi $\mathrm{AS}^{92} . \gamma \delta$ T cells contribute to liver-stage immunity induced by irradiated $P$. yoelii sporozoites $^{89}$. The role of these cells in immunity to P. chabaudi $i^{101-104}$ and $P$. yoelii ${ }^{21}$ blood stages does not seem to be crucial. Together with NK cells, $\gamma \delta$ T cells seem to be a source of IFN- $\gamma$ before the activation of antigen-specific $\alpha \beta$ T cells ${ }^{21}$. However, in the P. berghei ANKA model of cerebral malaria, $\gamma \delta$ T cells have been shown to contribute to the pathogenesis of cerebral disease $\mathrm{e}^{105}$. Malaria-reactive $\gamma \delta \mathrm{T}$-cell clones derived from irradiated $P$. yoelii sporozoite-immunized mice are MHC unrestricted, cross-react with various bacterial antigens, variably produce pro-inflammatory or antiinflammatory cytokines after non-specific activation in vitro and vary in their anti-parasitic activity ${ }^{106}$. More recently, $\gamma \delta \mathrm{T}$ cells have been shown to respond to P. yoelii-derived heat-shock proteins ${ }^{107}$.

Natural killer cells. NK cells are mainly found in peripheral blood, the spleen and bone marrow ${ }^{108}$, and might be ideally placed to deal with erythrocytic parasites. Both NK-cell-mediated cytotoxicity and IFN- $\gamma$ production are induced by infection with $P$. chabaudi chabaudi $\mathrm{AS}^{22}$, P. berghei $i^{109}$ or P. yoelii ${ }^{110}$, and production of IFN- $\gamma$ by NK cells is essential for the development of protective immunity to malaria ${ }^{22,23}$. Depletion of NK cells leads to a more rapid increase in blood parasitaemia and less efficient resolution of infection with P. chabaudi chabaudi AS in C57BL/6 mice ${ }^{22}$ and higher mortality in SCID mice infected with $P$. yoeli ${ }^{21}$. These NK-cell responses are IL-12 dependent as shown by studies in mice treated with recombinant IL-12 and depleted of NK cells during infection with $P$. chabaudi chabaudi $\mathrm{AS}^{17,22}$. In addition, a role for NK cells and IL-12 in protection induced by immunization with either irradiated sporozoites or DNA vaccines has been demonstrated ${ }^{111}$. In this paper, the authors argue that NK cells are part of an amplifying mechanism involved in antigen-specific adaptive immunity initiated by $\mathrm{CD}^{+} \mathrm{T}$ cells.

Recently published studies have indicated that NK cells are frequently the first cells to respond after in vitro exposure of human PBMCs to $P$. falciparuminfected erythrocytes ${ }^{12}$, although NK-cell IFN- $\gamma$ responses to $P$. falciparum are not seen in all donors. Activation of NK cells in vivo is also inferred from evidence that PBMCs from children with acute P. falciparum 
infections have enhanced lytic activity against the NK-sensitive cell line K562 (REF.113) and that serum levels of soluble granzyme A and IFN- $\gamma$ increase concomitantly just before the onset of clinical symptoms in experimental malaria infections ${ }^{42}$. Intriguingly, $\gamma \delta$ T cells and NKT cells start to make IFN- $\gamma$ only 24 to 48 hours after the peak of the NK-cell response (12-15 hours) and their activation is highly correlated with the NK-cell respons $\mathrm{e}^{112}$, indicating that NK cells might initiate a cascade of innate immune responses.

In many infections, NK-cell activation seems to occur mainly in a bystander manner - that is, in response to the production of cytokines such as IL-12 and IL- 18 by monocytes/macrophages and DCs ${ }^{114}$. In the case of NK-cell activation by P. falciparum, IL-12 and IL-18 are required but not sufficient for optimal IFN- $\gamma$ production ${ }^{112}$; direct contact between NK cells and parasitized erythrocytes is also required, and IFN- $\gamma$ production by NK cells correlates with high levels of expression of the lectin-like receptor CD94/NKG2A ${ }^{35}$. Taken together with the report that NK cells from malaria-exposed individuals can lyse P. falciparuminfected erythrocytes, indicating specific recognition of parasitized erythrocytes ${ }^{68}$, these observations show that at least two signals are required for activation of human NK cells by malaria parasites. One signal is cytokine mediated and the other requires direct contact between the NK cell and the infected erythrocyte. Although the ligands and receptors responsible for NK-cell activation are unknown at present, the recent report of an association between NK-cell reactivity to $P$. falciparum-infected erythrocytes and expression of specific alleles of one of the KIRs ${ }^{35}$ raises the intriguing possibility that genetic variation at the KIR locus might explain heterogeneity of human NK-cell responses to parasitized erythrocytes, and that human pathogens might express ligands for inhibitory or activating KIRs. These findings emphasize the need for large-scale population-based studies to address associations between KIR genotype and susceptibility to malaria.

\section{Genetic regulation of innate immunity?}

Highly virulent pathogens, particularly those such as $P$. falciparum that cause high mortality in pre-reproductive age groups, select for genetic traits that confer resistance to infection or disease. Selection over many thousands of years has led to variation between humans in their inherent susceptibility to malaria infection. Although much of this variation can be attributed to genetically determined physiological differences (such as sickle-cell trait, thalassaemia, glucose-6-phosphate deficiency and ovalocytosis) that affect the ability of the malaria parasite to infect and/or replicate in host cells (known as innate resistance); polymorphisms in immune-response-associated genes have been associated with differential outcomes of $P$. falciparum infection (TABLE 1).

Numerous epidemiological studies have now been carried out that report marked associations between particular polymorphisms in genes associated with the innate immune response and clinical outcome.
Of these, the relationship between TNF/lymphotoxin- $\alpha$ (LT- $\alpha$ ) polymorphisms and increased risk of cerebral malaria is by far the most reproducible and functionally plausible ${ }^{37,115-117}$. Functional polymorphisms in germline-encoded activating and inhibitory leukocyte receptors, including $\mathrm{KIRs}^{118,119}$ and cytotoxic T lymphocyte antigen 4 (CTLA4) ${ }^{120}$, and in PRRs, such as TLRs $^{121}$ and mannose-binding proteins ${ }^{122}$, are now being described and might modify innate immune responses.

Most recently, and of relevance to innate immunity, a promoter polymorphism in the gene encoding IL-12p40 (IL12B) has been associated with reduced levels of nitric-oxide production and increased mortality from cerebral malaria ${ }^{40}$, possibly indicating a role for IL-12 in the induction of protective, proinflammatory cytokine responses and activation of macrophages. However, these findings could not be replicated in a second study population, implying that the specific polymorphism identified might only be indirectly associated with the clinical and immunological outcome. Although linkage analysis has identified several candidate loci that control susceptibility to blood-stage malaria in mice, the exact identity and function of these genetic factors are unknown ${ }^{10}$.

\section{Balancing protection versus pathology}

The impact of innate responses on the outcome of human infection is not conclusively known and two opposing scenarios can be proposed. A robust and rapid pro-inflammatory response might enable the host to control the infection until the adaptive response takes over (as described earlier). This might be of most benefit during a primary infection but, given the extent of antigenic polymorphism, innate responses might also be required to control re-infections with a variant genotype until adaptive responses can be generated. However, a rapid and potent innate response might promote the development of severe malaria, either directly or by amplifying the effects of the adaptive response ${ }^{123}$. In support of this hypothesis, in infections with $P$. berghei in which overproduction of IFN- $\gamma$ and TNF/LT- $\alpha$ is associated with pathology ${ }^{124}$, IL-12 seems to have a pathogenic role ${ }^{125}$. In humans, a TNF promoter polymorphism $\left(T N F^{-308 A}\right)$, which is in linkage disequilibrium with specific polymorphisms in the LTA gene in the TNF/LTA locus and which increases LTA transcription ${ }^{126}$, is associated with increased risk of cerebral malaria in African children ${ }^{37,38}$. In reality, it is probable that innate responses can be both beneficial and potentially harmful, and the regulation of innate immunity might be an important component of the adaptive response.

The ability to control circulating levels of proinflammatory cytokines such that they facilitate parasite clearance but do not trigger pathology is one of the hallmarks of acquired immunity to malaria, but the mechanism by which this is achieved is unknown at present. In both mice ${ }^{127-129}$ and humans ${ }^{88,130}$, the key immunoregulatory cytokines seem to be IL-10 and transforming-growth factor- $\beta$ (TGF- $\beta$ ), both of which 
can be produced by cells of the innate (macrophages) and adaptive (T cells) immune systems, and either of which might contribute to the regulation of innate responses. TGF- $\beta$ present during the first two days of blood-stage infection in mice completely inhibits pro-inflammatory cytokine responses, leading to unconstrained parasite growth ${ }^{128,131}$. Our recent observation that malaria parasites can directly activate endogenous, latent TGF- $\beta$ to its bioactive form ${ }^{132}$ indicates that the parasite itself might be able to manipulate the innate response of the host. In other systems, TGF- $\beta$ has been shown to inhibit human IFN- $\gamma$ production by NK cells directly ${ }^{133}$, whereas IL-10 inhibits IL-12 production by DCs and macrophages, thereby downregulating IFN- $\gamma$ production by NK cells and $\mathrm{T}$ cells ${ }^{134}$.

\section{Implications for vaccine development}

As described earlier, accumulating evidence supports the concept that DCs, NK cells, NKT cells and possibly $\gamma \delta$ T cells and macrophages have important roles as effectors of innate immunity to malaria. These cell types can also modulate adaptive immunity due to their ability to produce regulatory cytokines. Cells of the innate immune system might, therefore, provide a valuable entry point for downstream T-cell activation
- an important consideration in the development of an effective vaccine against malaria ${ }^{2,3}$. For example, killing of hepatic schizonts by $\mathrm{CD} 8^{+} \mathrm{T}$ cells depends on NK cells and IL-12, indicating synergy between innate and adaptive immunity ${ }^{111}$. Owing to their ability to produce IL-12 in response to microbial stimuli, DCs might have a central role in the induction of $\mathrm{CD} 4^{+}$ $\mathrm{T}_{\mathrm{H}} 1$-cell responses, which are an essential component of adaptive immunity to blood-stage parasites ${ }^{2,3,59}$ (FIG. 3). NKT cells, which are activated during liver-stage as well as blood-stage malaria ${ }^{89,90}$, rapidly produce large amounts of IFN- $\gamma$ or IL- 4 in response to antigen-specific or polyclonal stimulation and have also been proposed to have the potential to influence adaptive immunity, including the polarization of $\mathrm{T}_{\mathrm{H}}$ cells ${ }^{135,136}$. Recently, Schofield and colleagues ${ }^{4}$ have shown that immunization with synthetic GPI induces protection against cerebral malaria in the P. berghei ANKA model. Sera from immunized mice were found to block in vitro TNF production by macrophages in response to crude extracts of $P$. falciparum schizonts, consistent with studies showing that NKT cells might provide help for antibody formation ${ }^{4,69,137}$.

Given the burden of malaria in developing countries, the need to develop an effective malaria vaccine cannot be overstated ${ }^{3}$. Despite the identification of protective

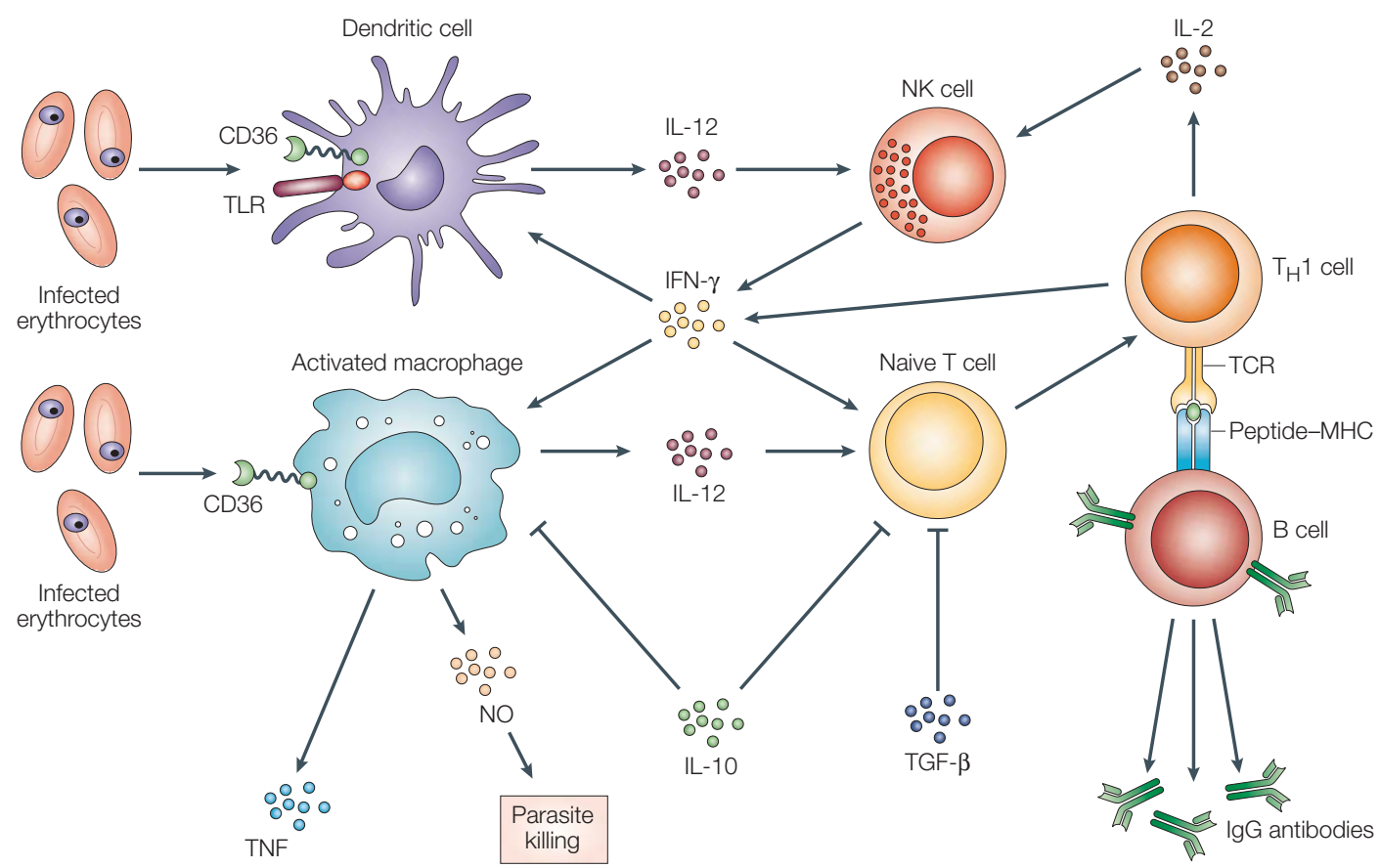

Figure 3 | Linking innate and adaptive immunity to blood-stage malaria. Possible regulation of adaptive immunity to blood-stage malaria by cytokines produced by cells of the innate immune response. In response to parasite ligands recognized by pattern-recognition receptors (PRRs), such as Toll-like receptors (TLRs) and CD36, or inflammatory cytokines, such as interferon- $\gamma(\mathrm{IFN}-\gamma)$, dendritic cells (DCs) mature and migrate to the spleen - the primary site of immune responses against blood-stage Plasmodium parasites. Maturation of DCs is associated with the upregulation of expression of MHC class II molecules, CD40, CD80, CD86 and adhesion molecules and the production of cytokines including interleukin-12 (IL-12). IL-12 activates natural killer (NK) cells to produce IFN- $\gamma$ and induces the differentiation of Thelper $1\left(T_{H} 1\right)$ cells. The production of cytokines, particularly IFN- $\gamma$, by NK cells results in DC maturation and enhances the effect of parasite-derived maturation stimuli, facilitating the clonal expansion of antigen-specific naive CD4+ $T$ cells. IL-2 produced by antigen-specific $T_{H} 1$ cells further activates NK cells to produce IFN- $\gamma$, which induces DC maturation and activates macrophages, further amplifying the adaptive immune response. Cytokines such as IL-10 and transforming growth factor- $\beta$ (TGF- $\beta$ ) negatively regulate both innate and adaptive responses. NO, nitric oxide; TCR, T-cell receptor; TNF, tumour-necrosis factor. 
antigens associated with the exoerythrocytic, blood and sexual stages of the Plasmodium parasite and the production of recombinant molecules, the efficacy of subunit vaccines based on these antigens has been disappointing in field trials. A possible strategy for enhancing the immunogenicity of recombinant malaria antigens might be the inclusion of cytokines, microbial products or synthetic compounds that activate the innate immune system. Many vaccine formulations use aluminum hydroxide (alum) as an adjuvant because it is one of few approved for use in humans. However, alum might not always be the most appropriate adjuvant given its potential to stimulate a $\mathrm{T}_{\mathrm{H}}$ 2-type immune response characterized by IgG1 in mice and its inability to induce cytotoxic T-cell responses ${ }^{76}$. By contrast, unmethylated $\mathrm{CpG}$ motifs, derived from bacteria and recognized by TLR9 (REF. 73), induce a type 1 pattern of cytokine production dominated by IL-12 and IFN- $\gamma$ with little secretion of type- 2 cytokines, and they have been found to be useful as adjuvants for vaccines, including peptide vaccines, against various pathogens ${ }^{76}$. As described earlier, unmethylated CpG motifs enhance the efficacy of a blood-stage malaria vaccine based on a crude antigen preparation delivered in alum in the model of $P$. chabaudi chabaudi AS malaria ${ }^{76}$. Near and colleagues $^{77}$ showed that immunization with a combination of $\mathrm{CpG}$ oligodeoxynucleotides and $P$. yoelii merozoite surface protein 1 of $19 \mathrm{kDa}\left(\mathrm{MSP}_{19}\right)$, a blood-stage antigen, in alum resulted in a mixed $\mathrm{T}_{\mathrm{H}} 1 / \mathrm{T}_{\mathrm{H}} 2$-cell response and improved vaccine efficacy. In a study by $\mathrm{Su}$ et al $^{.76}$, recombinant IL-12 absorbed to alum enhanced the efficacy of a crude antigen vaccine by inducing a $\mathrm{T}_{\mathrm{H}} 1$-cell immune response; protection was found to depend on $\mathrm{CD} 4^{+} \mathrm{T}$ cells, IFN- $\gamma$ and $\mathrm{B}$ cells. Incorporation of a plasmid encoding mouse granulocyte-macrophage colony-stimulating factor (GM-CSF) in a DNA vaccine against the circumsporozoite protein of $P$. yoelii enhanced vaccine efficacy by increasing T-cell proliferation and enhancing the production of IFN- $\gamma$, IL-2 and antibodies ${ }^{138}$. Direct or indirect activation of CD1d-restricted NKT cells using $\alpha$-GalCer as an adjuvant to enhance vaccine-induced immunity to pre-erythrocytic parasites provides another example of the feasibility of using adjuvants that target the innate immune system to promote the efficacy of vaccine-induced immunity to malaria ${ }^{89}$. Additional studies are warranted in this area as novel agents capable of modifying the innate immune response are identified.

\section{Conclusion}

Innate and adaptive immunity are inextricably linked as the cytokines produced by cells of the innate system modify the outcome of the adaptive response (FIG. 3). This has important implications for vaccine design and immunotherapy. In mice, exogenous manipulation of the innate response can limit acute protozoan infections, synergize with chemotherapeutic agents to facilitate parasite clearance and augment the effects of partially effective vaccines ${ }^{52}$. Given the therapeutic and prophylactic implications, direct evaluation of the innate response to malaria in humans and its impact on acquired immunity is required.
1. Malaria: Parasite Biology, Pathogenesis and Protection. (ed. Sherman, I. W.) (ASM Press, Washington DC, 1998).

2. Good, M. F. \& Doolan, D. L. Immune effector mechanisms in malaria. Curr. Opin. Immunol. 11, 412-419 (1999).

3. Good, M. F. Towards a blood-stage vaccine for malaria: are we following all the leads? Nature Rev. Immunol. 1, 117-125 (2001).

4. Schofield, L et al. Synthetic GPI as a candidate anti-toxic vaccine in a model of malaria. Nature 418, 785-789 (2002). This paper shows a causal association between malarial glycosylphosphatidylinositol (GPI) and severe pathology in mice.

5. Franks, S., et al. Frequent and persistent asymptomatic Plasmodium falciparum infections in African infants characterised by multilocus genotyping. J. Infect. Dis. 183, 796-804 (2001).

6. Miller, L. H., Baruch, D. I., Marsh, K. \& Doumbo, O. K. The pathogenic basis of malaria. Nature 415, 673-679 (2002).

7. Kwiatkowski, D., et al. The malarial fever response pathogenesis, polymorphism and prospects for intervention. Ann. Trop. Med. Parasitol. 91, 533-542 (1997).

8. Hunt, N. \& Grau, G. E. Cytokines: accelerators and brakes in the pathogenesis of cerebral malaria. Trends Immunol. $\mathbf{2 4}$ 491-499 (2003).

9. Langhorne, J., Quin, S. J. \& Sanni L. A. Mouse models of blood-stage malaria infections: immune responses and cytokines involved in protection and pathology. Chem. Immunol. 80, 204-228 (2002).

10. Fortin, A., Stevenson, M. M. \& Gros, P. Susceptibility to malaria as a complex trait: huge pressure from a tiny creature. Hum. Mol. Genetics 11, 2469-2478 (2002).

11. de Souza, J. B. \& Riley, E. M. Cerebral malaria: the contribution of studies in animals to our understanding of immunopathogenesis. Microbes Infect. 4, 291-300 (2002).

12. Shear, H. L., Marino, M. W., Wanidworanun, C. J., Berman, W. \& Nagel, R. L. Correlation of increased expression of intercellular adhesion molecule-1, but not high levels of tumor necrosis factor- $\alpha$, with lethality of Plasmodium yoelii $17 \mathrm{XL}$, a rodent model of cerebral malaria. Am. J. Trop. Med. Hyg. 59, 852-858 (1998).
13. McQueen, K. \& Parham, P. Variable receptors controlling activation and inhibition of NK cells. Curr. Opin. Immunol. 14 615-621 (2002).

14. Colucci, F., Di Santo, J. P. \& Leibson, P. J. Natural killer cell activation in mice and men: different triggers for similar weapons? Nature Immunol. 3, 807-813 (2002).

15. Shortman, K. \& Liu, Y.-J. Mouse and human dendritic cell subtypes. Nature Rev. Immunol. 2, 151-161 (2002).

16. Su, Z. \& Stevenson, M. M. IL-12 is required for antibodymediated protective immunity against blood-stage Plasmodium chabaudi AS malaria. J. Immunol. 168 1348-1355 (2002).

This is the first paper to show the importance of a T helper $1\left(T_{H} 1\right)$-cell response for protective immunity during both the acute and chronic phases of bloodstage infection with Plasmodium chabaudi chabaudi AS, and the role of interleukin-12 (IL-12) in inducing cell-mediated and antibody-mediated immunity to malaria.

17. Stevenson, M. M., Su, Z., Sam, H. \& Mohan, K. Modulation of host responses to blood-stage malaria by interleukin-12: from therapy to adjuvant activity. Microbes Infect. 3, 49-59 (2001).

18. van der Heyde, H. C.. Pepper, B., Batchelder, J., Cigel, F. \& Weidanz, W. P. The time course of selected malarial infections in cytokine-deficient mice. Exp. Parasitol. 85 206-213 (1997)

References 18 and 20 provide evidence for the essential role of interferon- $\gamma($ IFN- $\gamma)$ in protective immunity to blood-stage infection with $P$. chabaudi species and Plasmodium yoelii.

19. Su, Z. \& Stevenson, M. M. Central role of endogenous $\gamma$-interferon in protective immunity against blood-stage Plasmodium chabaudi AS infection. Infect. Immun. 68, 4399-4406 (2000).

20. Meding, S. J. \& Langhorne, J. CD4 ${ }^{+} T$ cells and B cells are necessary for the transfer of protective immunity to Plasmodium chabaudi chabaudi. Eur. J. Immunol. 21, 1433-1438 (1991).

21. Choudhury, H., Sheikh, N., Bancroft, G., Katz, D. \& De Souza, J. Early nonspecific immune responses and immunity to blood-stage nonlethal Plasmodium yoelii malaria. Infect. Immun. 68, 6127-6132 (2000).

22. Mohan, K. Moulin, P. \& Stevenson, M. M. Natural killer cell cytokine production, not cytotoxicity, contributes to resistance against blood-stage Plasmodium chabaudi AS infection. J. Immunol. 159, 4990-4998 (1997).

23. de Souza, J. B., Williamson, K. H., Otani, T. \& Playfair, J. H. L. Early $\gamma$-interferon responses in lethal and nonlethal murine blood stage malaria. Infect. Immun. 65, 1593-1598 (1997). References 21-23 show that the production of IFN- $\gamma$ by natural killer (NK) cells and possibly $\gamma \delta$ T cells early in infection is important in activating the appropriate $\mathrm{CD}^{+} \mathrm{T}_{\mathrm{H}}$-cell subset during blood-stage malaria in mice.

24. Molineaux, L., Trauble, M., Collins, W., Jeffery, G. \& Dietz, K. Malaria therapy reinoculation data suggest individual variation of an innate immune response and independent acquisition of antiparasitic and antitoxic immunities. Trans. R. Soc. Trop Med. Hyg 96, 205-209 (2002).

25. Luty, A., Kun, J. \& Kremsner, P. Mannose-binding lectin plasma levels and gene polymorphisms in Plasmodium falciparum malaria. J. Infect. Dis. 178, 1221-1224 (1998).

26. Burgner, D., et al. Nucleotide and haplotypic diversity of the NOS2A promoter region and its relationship to cerebral malaria. Hum. Genetics 112, 379-386 (2003).

27. Kun, J. et al. Nitric oxide synthase $2^{\text {Lambarene }}$ (G-954C), increased nitric oxide production, and protection against malaria. J. Infect. Dis. 184, 330-336 (2001).

28. Hobbs, M. et al. A new NOS2 promoter polymorphism associated with increased nitric oxide production and protection from severe malaria in Tanzanian and Kenyan children. Lancet 360, 1468-1475 (2002).

29. Hill, A. V. S. et al. Common West African HLA antigens are associated with protection from severe malaria. Nature 352 595-600 (1991)

30. Koch, O. et al. IFNGR1 gene promoter polymorphisms and susceptibility to cerebral malaria. J. Infect. Dis. 185, 1684-1687 (2002)

31. Aucan, C. et al. Interferon- $\alpha$ receptor-1 (IFNAR1) variants are associated with protection against cerebral malaria in The Gambia. Genes Immun. 4, 275-282 (2003). 
32. Omi, K. et al. CD36 polymorphism is associated with protection from cerebral malaria. Am. J. Hum. Genet. 72 364-374 (2003)

33. Aitman, T. et al. Malaria susceptibility and CD36 mutation Nature 405, 1015-1016 (2000)

34. Pain, A. et al. A non-sense mutation in CD36 gene is associated with protection from severe malaria. Lancet $\mathbf{3 5 7}$, 1502-1503 (2001)

35. Artavanis-Tsakonas, K. et al. Activation of a subset of human natural killer cells upon contact with Plasmodium falciparum-infected erythrocytes. J. Immunol. 171. 5396-5405 (2003)

36. Sabeti, P. et al. CD4OL association with protection from severe malaria. Genes Immun. 3, 286-291 (2002).

37. McGuire, W., Hill A. V. S., Allsopp, C. E. M., Greenwood, B. M. \& Kwiatkowski, D. Variation in the TNF $\alpha$ promoter region associated with susceptibility to cerebral malaria. Nature $\mathbf{3 7 1}$, 508-511 (1994).

This study was the first to show a relationship between a cytokine gene polymorphism and risk of severe malaria, indicating the need to regulate inflammatory cytokine levels to prevent severe pathology.

38. Knight, J. C. et al. A polymorphism that affects OCT-1 binding to the TNF promoter region is associated with severe malaria. Nature Genet. 22, 145-150 (1999).

39. Luoni, G. et al. Antimalarial antibody levels and IL-4 polymorphism in the Fulani of West Africa. Genes Immun. 2, 411-414 (2001).

40. Morahan, G., et al. A promoter polymorphism in the gene encoding interleukin-12 p40 (IL12B) is associated with mortality from cerebral malaria and with reduced nitric oxide production. Genes Immun. 3, 414-418 (2002).

41. Kwiatkowski, D. Genetic susceptibility to malaria getting complex. Curr. Opin. Genet. Dev. 10, 320-324 (2000).

42. Hermsen, C. et al. Circulating concentrations of soluble granzyme $A$ and $B$ increase during natural and experimenta Plasmodium falciparum infections. Clin. Exp. Immunol. 132 467-472 (2003).

43. Scragg, I., Hensmann, M., Bate, C. \& Kwiatkowski, D. Early cytokine induction by Plasmodium falciparum is not a classical endotoxin-like process. Eur. J. Immunol. 29 2636-2644 (1999)

44. Bruce, M. \& Day, K. P. Cross-species regulation of Plasmodium parasitemia in semi-immune children from Papua New Guinea. Trends Parasitol. 19, 271-277 (2003). This article describes how innate immune responses can control, but not eliminate, malaria infections and that innate effector mechanisms are equally effective against different species and strains of malaria.

45. Kwiatkowski, D. \& Nowak, M. Periodic and chaotic hostparasite interactions in human malaria. Proc. Natl Acad. Sci. USA 88, 5111-5113 (1991).

46. Ritchie, T. L. Interactions between malaria parasites infecting the same vertebrate hosts. Parasitol. 96, 607-639 (1988).

47. Maitland, K., Williams, T. N. \& Newbold, C. Plasmodium vivax and $P$. falciparum: biological interactions and the possibility of cross-species immunity. Parasitol. Today 13 227-231 (1997).

48. Ewald, P. W. Evolution of Infectious Disease (Oxford University Press, New York, 1994).

49. Scharton-Kersten, T., Afonso, L., Wysocka, M., Trinchieri, G. \& Scott, P. IL-12 is required for natural killer cell activation and subsequent Thelper 1 cell development in experimental leishmaniasis. J. Immunol. 154, 5320-5330 (1995).

50. Biron, C. A. Activation and function of natural killer responses during viral infections. Curr. Opin. Immunol. 9, 24-34 (1997).

51. Unanue, E. R. Inter-relationship among macrophages, natural killer cells, and neutrophils in early stage of Listeria resistance. Curr. Opin. Immunol. 9, 35-43 (1997).

52. Scharton-Kersten, T. \& Sher, A. Role of natural killer cells in innate resistance to protozoan infections. Curr. Opin. Immunol. 9, 44-51 (1997).

53. Quin, S. J. et al. Low CD4+ $\mathrm{T}$ cell responses to the $\mathrm{C}$-terminal region of the malaria merozoite surface protein-1 may be attributed to processing within distinct MHC class pathways. Eur. J. Immunol. 31, 72-81 (2001).

54. Luyendyk, J., Olivas, O. R., Ginger, L. A. \& Avery, A. C. Antigen-presenting cell function during Plasmodium yoelii infection. Infect Immun. 70, 2941-2949 (2002).

55. McGregor, I. A. \& Barr, M. Antibody response to tetanus toxoid inoculation in malarious and non-malarious Gambian children. Trans. R. Soc. Med. Hyg. 56, 364-367 (1962).

56. Greenwood, B. M., Bradley-Moore, A. M., Palit, A. \& Bryceson, A. D. M. Immunosuppression in children with malaria. Lancet 1, 169-172 (1972).

57. Serghides, I., Smith, T. G., Patel, S. N. \& Kain, K. C. CD36 and malaria: friends or foes? Trends Parasitol. 19, 461-469 (2003)
58. Guermonprez, P., Valladeau, J., Zitvogel, L., Théry, C. \& Amigorena S. Antigen presentation and T cell stimulation by dendritic cells. Annu. Rev. Immunol. 20, 621-667 (2002).

59. Sher, A., Pearce, E. \& Kaye, P. Shaping the immune response to parasites: role of dendritic cells. Curr. Opin. Immunol. 15, 421-429 (2003).

60. Robinson, B., Welch, T. \& Smith, J. Widespread functional specialization of Plasmodium falciparum erythrocyte membrane protein 1 family members to bind CD36 analysed across a parasite genome. Mol. Microbiol. 47 1265-1278 (2003).

61. Urban, B. C. et al. Plasmodium falciparum-infected erythrocytes modulate the maturation of dendritic cells. Nature 400, 73-77 (1999).

This was the first report of the ability of Plasmodium parasites to inhibit dendritic-cell (DC) maturation and antigen-presenting function in vitro.

62. Eda, S. \& I. Sherman. Cytoadherence of malaria-infected red blood cells involves exposure of phosphatidylserine. Cell Physiol. Biochem. 12, 373-384 (2002).

63. Tachado, S. D. et al. Glycophosphatidylinositol toxin of Plasmodium induces nitric oxide synthase expression in macrophages and vascular endothelial cells by a protein tyrosine kinase-dependent and protein kinase C-dependent signaling pathway. J. Immunol. 156, 1897-1907 (1996).

64. Vijaykumar, M., Naik, R. \& Gowda, D. Plasmodium falciparum glycosylphosphatidylinositol-induced TNF- $\alpha$ secretion by macrophages is mediated without membrane insertion or endocytosis. J. Biol. Chem. 276, 6909-6912 (2001).

65. Adachi, K. et al. Plasmodium berghei infection in mice induces liver injury by an IL-12- and toll-like receptor/myeloid differentiation factor 88 -dependent mechanism. J. Immunol. 167, 5928-5934 (2001).

66. Behr, C. et al. Plasmodium falciparum stimuli for human $\gamma \delta \mathrm{T}$ cells are related to the phophorylated antigens of mycobacteria. Infect. Immun. 64, 2892-2896 (1996).

67. Pichyangkul, S. et al. Activation of $\gamma \delta$ T cells in malaria: interaction of cytokines and a schizont-associated Plasmodium falciparum antigen. J. Infect. Dis. 176, 233-241 (1997)

68. Orago, A. \& Facer, C. Cytotoxicity of human natural killer (NK) cell subsets for Plasmodium falciparum erythrocytic schizonts: stimulation by cytokines and inhibition by neomycin. Clin. Exp. Immunol. 86, 22-29 (1991).

69. Schofield, L. et al. CD1d-restricted immunoglobulin G formation to GPI-anchored antigens mediated by NKT cells. Science 283, 225-229 (1999).

70. Lee, S., Gonzalez-Aseguinolaza, G. \& Nussenzweig, M. Disseminated candidiasis and hepatic malarial infection in mannose-binding-lectin-A-deficient mice. Mol. Cell Biol. 22, 8199-8203 (2002).

71. Klabunde, J. et al. Recognition of Plasmodium falciparum proteins by mannan-binding lectin, a component of the human innate immune system. Parasitol. Res. 88, 113-117 (2002).

72. Claudianos, C. et al. A malaria scavenger receptor-like protein essential for parasite development. Mol. Microbiol. 45, 1473-1484 (2002).

73. Takeda, K., Kaisho, T. \& Akira, S. Toll-like receptors Annu. Rev. Immunol. 21, 335-376 (2003).

74. Campos, M. A. et al. Activation of Toll-like receptor-2 by glycosylphosphatidylinositol anchors from a protozoan parasite. J. Immunol. 167, 416-423 (2001).

75. Gramzinski, R. et al. Interleukin-12- and $\gamma$-interferondependent protection against malaria conferred by $\mathrm{CpG}$ oligodeoxynucleotide in mice. Infect. Immun. $\mathbf{6 9}$, 1643-1649 (2001).

76. Su, Z, Tam, M.-F., Jankovic, D. \& Stevenson, M. M. Vaccination with novel immunostimulatory adjuvants against blood-stage malaria in mice. Infect. Immun. $\mathbf{7 1}$ 5178-5187 (2003).

77. Near, K. A., Stowers, A. W., Jankovic, D. \& Kaslow, D. C. Improved immunogenicity and efficacy of the recombinan 19-kilodalton merozoite surface protein 1 by addition of oligodeoxynucleotide and aluminum hydroxide gel in a murine malaria vaccine model. Infect. Immun. 70, 692-701 (2002). The first example of a pathogen-associated activator of the innate immune response that enhances vaccine-induced immunity against Plasmodium.

78. Ocana-Morgner, C., Mota, M. \& Rodriguez, A. Malaria blood stage suppression of liver stage immunity by dendritic cells. J. Exp. Med. 197, 143-151 (2003).

79. Perry, J. A., Rush, A., Wilson, R. J., Olver, C. S. \& Avery, A. C. Dendritic cells from malaria-infected mice are fully functional APC. J. Immunol. 172, 475-482 (2004).

80. Seixas, E., Cross, C., Quin, S. \& Langhorne, J. Direct activation of dendritic cells by the malaria parasite, Plasmodium chabaudi chabaudi. Eur. J. Immunol. 31 2970-2978 (2001).
81. Coban, C., Ishii, K., Sullivan, D. \& Kumar, N. Purified malaria pigment (hemozoin) enhances dendritic cell maturation and modulates the isotype of antibodies induced by a DNA vaccine. Infect. Immun. 70, 3939-3943 (2002).

82. Urban, B. et al. Peripheral blood dendritic cells in children with acute Plasmodium falciparum malaria. Blood 98 2859-2861 (2001)

83. Singh, R. P. et al. The role of IL-18 in blood-stage immunity against murine malaria Plasmoidum yoelii 265 and Plasmodium berghei ANKA. J. Immunol. 168 4674-4681 (2002)

84. Luty, A. et al. Low interleukin-12 activity in severe Plasmodium falciparum malaria. Infect. Immun. 68, 3905-3915 (2000)

85. Malaguarnera, L. et al. Increased levels of interleukin-12 in Plasmodium falciparum malaria: correlation with the severity of disease. Parasite Immunol. 24, 387-389 (2002).

86. Perkins, D., Weinberg, J. \& Kremsner, P. Reduced interleukin-12 and transforming growth factor- $\beta 1$ in severe childhood malaria: relationship of cytokine balance with disease severity. J. Infect. Dis. 182, 988-992 (2000).

87. Malaguarnera, L., Pignatelli, S., Musumeci, M., Simpore, J. \& Musumeci, S. Plasma levels of interleukin-18 and interleukin-12 in Plasmodium falciparum malaria. Parasite Immunol. 24, 489-492 (2002).

88. Dodoo, D. et al. Absolute levels and ratios of proinflammatory and anti-inflammatory cytokine production in vitro predict clinical immunity to $P$. falciparum malaria. J. Infect. Dis. 185, 971-979 (2002).

89. Schmieg, J., Gonzalez-Asequinolaza, G. \& Tsuij, M. The role of natural killer $T$ cells and other $T$ cell subsets against infection by the pre-erythrocytic stages of malaria parasites. Microbes Infect. 5, 499-506 (2003).

90. Hansen, D., Siomos, M., Buckingham, L., Scalzo, A \& Schofield, L. Regulation of murine cerebral malaria pathogenesis by CD1d-restricted NKT cells and the natural killer complex. Immunity 18, 391-402 (2003).

91. Procopio, D. O. et al. Glycosylphosphatidylinositol-anchored mucin-like glycoproteins from Trypanosoma cruzi bind to CD1d but do not elicit dominant innate or adaptive immune responses via the CD1d/NKT cell pathway. J. Immunol. 169, 3926-3933 (2002).

92. Langhorne, J., Morris-Jones, S., Casabo, L. G. \& Goodier, M. The response of $\gamma \delta$ T cells in malaria infections: a hypothesis. Res. Immunol. 145, 429-436 (1994).

93. Hviid, L. et al. Perturbation and proinflammatory type activation of $\mathrm{V} \delta 1^{+} \gamma \delta \mathrm{T}$ cells in African children with Plasmodium falciparum malaria. Infect. Immun. 69 3190-3196 (2001).

94. Hensmann, M. \& Kwiatkowski, D. Cellular basis of early cytokine response to Plasmodium falciparum. Infect. Immun. 69, 2364-2371 (2001).

95. Elloso, M. M., van der Heyde, H. C., Vande Waa, J. A., Manning, D. D. \& Weidanz, W. P. Inhibition of Plasmodium falciparum in vitro by human $\gamma \delta$ T cells. J. Immunol. 153, 1187-1194 (1994).

96. Constant, P. et al. Stimulation of human $\gamma \delta$ T cells by nonpeptidic mycobacterial ligands. Science $\mathbf{2 6 4}$ 267-270 (1994)

97. Tanaka, Y. et al. Natural and synthetic non-peptide antigens recognized by human $\gamma \delta$ T cells. Nature $\mathbf{3 7 5}, \mathbf{1 5 5}-158$ (1995)

98. Elloso, M. M., van der Heyde, H. C., Troutt, A., Manning, D. D. $\&$ Weidanz, W. P. Human $\gamma \delta$ T cell subset-proliferative response to malarial antigen in vitro depends on $\mathrm{CD}^{+} \mathrm{T}$ cells or cytokines that signal through components of the IL-2R. J. Immunol. 157, 2096-2102 (1996).

99. Waterfall, M., Black, A. \& Riley, E. $\gamma \delta^{+}$T cells preferentially respond to live rather than killed malaria parasites. Infect. Immun. 66, 2393-2398 (1998).

100. Morris-Jones, S., Goodier, M. \& Langhorne, J. The response of $\gamma \delta$ T cells to Plasmodium falciparum is dependent on activated $\mathrm{CD} 4{ }^{+} \mathrm{T}$ cells and the recognition of $\mathrm{MHC}$ class I molecules. Immunol. 89, 405-412 (1996).

101. van der Heyde, H. C. et al. $\gamma \delta$ T cells function in cell-mediated immunity to acute blood-stage Plasmodium chabaudi adami malaria. J. Immunol. 154, 3985-3990 (1995).

102. Seixas, E. \& Langhorne, J. $\gamma \delta$ T cells contribute to control of chronic parasitemia in Plasmodium chabaudi infections in mice. J. Immunol. 162, 2837-2841 (1999).

103. Langhorne, J., Mombaerts, P. \& Tonegawa, S. $\alpha \beta$ and $\gamma \delta$ $T$ cells in the immune response to the erythrocytic stages of malaria in mice. Int. Immunol. 7, 1005-1011 (1995).

104. Weidanz, W. et al. Plasticity of immune responses suppressing parasitemia during acute Plasmodium chabaudi malaria. J. Immunol. 162, 7383-7388 (1999).

105. Yanez, D., Batchelder, J., van der Heyde, H., Manning, D. $\&$ Weidanz, W. $\gamma \delta$ T-cell function in pathogenesis of cerebral malaria in mice infected with Plasmodium berghei ANKA Infect. Immun. 67, 446-448 (1999). 
106. Tsuji, M. et al. Phenotypic and functional properties of murine $\gamma \delta \mathrm{T}$ cell clones derived from malaria immunized $\alpha \beta$ T cell-deficient mice. Int. Immunol. 8, 359-366 (1996).

107. Kopacz, J. \& Kumar, N. Murine $\gamma \delta$ T lymphocytes elicited during Plasmodium yoelii infection respond to Plasmodium heat shock proteins. Infect. Immun. 67, 57-63 (1999).

108. Moretta, A., Bottino, C., Mingari, M., Biassoni, R. \& Moretta, L. What is a natural killer cell? Nature Immunol. 3, 6-8 (2002)

109. Ojo-Amaize, E., Vilcek, J., Cochrane, A. \& Nussenzweig, R. Plasmodium berghei sporozoites are mitogenic for murine T cells, induce interferon, and activate natural killer cells. J. Immunol. 133, 1005-1009 (1984).

110. Pasquetto, V., Guidotti, L., Kakimi, K., Tsuji, M. \& Chisari, F. Host-virus interactions during malaria infections in hepatitis B virus transgenic mice. J. Exp. Med. 192, 529-536 (2000).

111. Doolan, D. L. \& Hoffman, S. L. IL-12 and NK cells are required for antigen-specific adaptive immunity agains malaria initiated by $\mathrm{CD}^{+} \mathrm{T}$ cells in the Plasmodium yoeli model. J. Immunol. 163, 884-892 (1999).

112. Artavanis-Tsakonas, K. \& Riley, E. M. Innate immune response to malaria: rapid induction of IFN- $\gamma$ from human NK cells by live Plasmodium falciparum-infected erythrocytes. J. Immunol. 169, 2956-2963 (2002).

This paper provides evidence for direct, contactdependent recognition of Plasmodium falciparuminfected erythrocytes by NK cells, implying that infected erythrocytes express ligands for NK-cell receptors.

113. Theander, T. G. et al. Enhancement of human natural cytotoxicity by Plasmodium falciparum antigen activated lymphocytes. Acta Trop. 44, 415-422 (1987).

114. Biron, C. A., Nguyen, K. B., Pien, G. C., Cousens, L. P. \& Salazar-Mather, T. P. Natural killer cells in antiviral defense: function and regulation by innate cytokines. Annu. Rev. Immunol. 17, 189-220 (1999).

115. Wattavidanage, J. et al. TNF- $\alpha^{\star} 2$ marks high risk of severe disease during Plasmodium falciparum malaria and other infections in Sri Lankans. Clin. Exp. Immunol. 115, 350-355 (1999).

116. Aidoo, M. et al. Tumor necrosis factor- $\alpha$ promoter variant 2 (TNF2) is associated with pre-term delivery, infant mortality, and malaria morbidity in western Kenya: Asembo Bay Cohort Project IX. Genet. Epidemiol. 21, 201-211 (2001).

117. Ubalee, R. et al. Strong association of a tumor necrosis factor- $\alpha$ promoter allele with cerebral malaria in Myanmar. Tissue Antigens 58, 407-410 (2001).

118. Uhrberg, M. et al. Human diversity in killer cell inhibitor receptor genes. Immunity 7, 753-763 (1997)

119. Rajalingam, R., Gardiner, C., Canavez, F., Vilches, C. \& Parham, P. Identification of seventeen novel KIR variants: fourteen of them from two non-Caucasian donors. Tissue Antigens 57, 22-31 (2001).
120. Akalin, E. \& Murphy, B. Gene polymorphisms and transplantation. Curr. Opin. Immunol. 13, 572-576 (2001).

121. Arbour, N. et al. TLR4 mutations are associated with endotoxin hyporesponsiveness in humans. Nature Genet. $\mathbf{2 5}$ 187-191 (2000).

122. Summerfield, J. et al. Mannose binding protein gene mutations associated with unusual and severe infections in adults. Lancet 345, 886-889 (1995).

123. Riley, E. M. Is T cell priming required for initiation of pathology in malaria infections? Immunol. Today $\mathbf{2 0}$ 228-233 (1999).

124. Engwerda, C. et al. Locally upregulated lymphotoxin $\alpha$, not systemic tumor necrosis factor $\alpha$, is the principle mediator of murine cerebral malaria. J. Exp. Med. 195 1371-1377 (2002).

125. Yoshimoto, T. et al. Pathogenic role of IL-12 in blood-stage murine malaria lethal strain Plasmodium berghei NK65 infection. J. Immunol. 160, 5500-5505 (1998).

126. Knight, J. C., Keating, B. J., Rockett, K. A. \& Kwiatkowski, D. P. In vivo characterization of regulatory polymorphisms by allele-specific quantification of RNA polymerase loading. Nature Genet. 33, 469-475 (2003).

127 Omer, F. M. \& Riley, E. M. TGF- $\beta$ production is inversely correlated with severity of murine malaria infection. J. Exp. Med. 188, 39-48 (1998). This was the first study to show a causal relationshi between the balance of pro-inflammatory and antiinflammatory cytokines and the outcome of malaria infections.

128. Omer, F., de Souza, J. \& Riley, E. Differential induction of TGF- $\beta$ regulates pro-inflammatory cytokine production and determines the outcome of lethal and nonletha Plasmodium yoelii infections. J. Immunol. 171, 5430-5436 (2003)

129. Li, C., Sanni, L. A., Omer, F. M., Riley, E. M. \& Langhorne, J. Pathology and mortality of Plasmodium chabaudi chabaudi infection in IL-10-deficient mice is ameliorated by anti-TNF- $\alpha$ and exacerbated by anti-TGF- $\beta$ antibodies. Infect. Immun. $\mathbf{7 1}$ 4850-4856 (2003)

130. Kurtzhals, J. A. L. et al. Low concentrations of interleukin 10 in severe malarial anaemia compared with cerebral and uncomplicated malaria. Lancet 351, 1768-1772 (1998).

131. Tsutsui, N. \& Kamiyama,T. Transforming growth factor $\beta$-induced failure of resistance to infection with bloodstage Plasmodium chabaudi in mice. Infect. Immun. $\mathbf{6 7}$. 2306-2311 (1999).

132. Omer, F. M., de Souza, J. B., Corran, P. H., Sultan, A. A. $\&$ Riley, E. M. Activation of transforming growth factor- $\beta$ by malaria parasite-derived metalloproteases and a thrombospondin-like molecule. J. Exp. Med. 198, 1817-1827 (2003).
133. Ortaldo, J. R. et al. Mechanistic studies of transforming growth factor- $\beta$ inhibition of IL-2-dependent activation of CD3- large granular lymphocyte functions. Regulation of IL-2R $\beta$ (p75) signal transduction. J. Immunol. 146 3791-3798 (1991).

134. D'Andrea, A., Aste-Amezaga, M., Valiante, N., Ma, X., Kubin, M. \& Trinchieri, G. Interleukin-10 (IL-10) inhibits human lymphocyte interferon $\gamma$-production by suppressing natural killer cell stimulatory factor/L-12 synthesis in accessory cells. J. Exp. Med. 178, 1041-1048 (1993).

135. Roura-Mir, C. \& Moody, B. Sorting out self and microbial lipid antigens for CD1. Microbes Immun. 5, 1137-1148 (2003).

136. Sköld, M. \& Behar, S. M. Role of CD1d-restricted NKT cells in microbial immunity. Infect. Immun. 71, 5447-5455 (2003).

137. Hansen, D. S. et al. CD1d-restricted NKT cells contribute to malaria splenomegaly and enhance parasite-specific antibody responses. Eur. J. Immunol. 33, 2588-2598 (2003)

138. Weiss, W. R. et al. A plasmid encoding murine granulocyte-macrophage colony stimulating factor increases protection conferred by a malaria DNA vaccine. J. Immunol. 161, 2325-2332 (1998).

\section{Acknowledgements}

We gratefully acknowledge the assistance of M. Tam in the preparation of this manuscript. E.M.R. would like to acknowledge the contributions of K. Artavanis-Tsakonas, M. Walther, D. Korbel, D. Davis, K. McQueen and P. Parham to studies on innate immunity in her laboratory. The work is supported by the UK Medical Research Council, The Wellcome Trust, Boehringer Ingelheim Funds, The Burroughs Wellcome Fund and the Canadian Institutes of Health Research.

Competing interests statement

The authors declare that they have no competing financial interests.

\section{(2) Online links}

\section{DATABASES}

The following terms in this article are linked online to:

LocusLink: http://www.ncbi.nlm.nih.gov/LocusLink/ CD36 | CD40 | CD80 | CD83 | CD86 | CTLA4 | GM-CSF | ICAM1 | IFN- $\gamma$ | IL-2 | IL-4 | IL-8 | IL-10 | IL-12 | LT- $\alpha$ | Myd88 | TGF- $\beta$ | Tlr2 TIr4 | TIr6 | TNF

\section{FURTHER INFORMATION}

World Health Organization web site: http://www.who.ch Literature and links detailing genetic determinants of susceptibility to malaria:

http://www.gmap.net/topics/malaria.htm

Access to this interactive links box is free online. 